\title{
BARCELONA: UNA CIBERCIUDAD EN TRÁNSITO
}

\section{Pep Vivas i Elias ${ }^{1}$}

Estudis de Psicología i Ciències de l'Educació

Universitat Oberta de Catalunya

\author{
Ramon Ribera-Fumaz \\ Estudis d'Economia i Empresa \\ Universitat Oberta de Catalunya
}

\section{Óscar López Catalán ${ }^{2}$}

Departament d'Antropologia Social

Universitat Autònoma de Barcelona

\section{Isabel Pellicer Cardona}

Departament de Psicologia Social

Universitat Autònoma de Barcelona

Remisión Artículo: 21-01-2008

Remisión definitiva: 14-02-2008

Palabras Clave: ciberciudad, espacio, nuevas tecnologías, Barcelona

Resumen: El auge de las nuevas tecnologías en el contexto urbano provoca que centremos nuestra atención en unos espacios urbanos que permiten la interconexión y el movimiento de las personas en las ciberciudades actuales.

Esta es la intención del presente trabajo. Así pues, en un primer momento y a través de un ejemplo, presentamos una realidad urbana que pone de manifiesto la influencia que la tecnología tiene sobre la urbe y sobre todo como la tecnología mediatiza nuestras formas de relacionarnos, de interaccionar, de movernos, etc.

En definitiva, en este artículo vamos a analizar, en el segundo apartado, la ciberciudad actual o la ciudad del presente- a través de algunos espacios urbanos donde la tecnología está muy presente. En el tercer apartado presentamos lo que nosotros denominamos como espacios de sociabilidad transitoria como espacios característicos de las urbes actuales. A continuación, exponemos tres ejemplos estos espacios en el contexto de Barcelona. Por último, en el quinto apartado explicamos nuestro método de trabajo para investigar las ciberciudades: la etnografía urbana. Para ello, hacemos una definición inicial de un posible lugar donde realizar nuestra práctica etnográfica: el metro de Barcelona. El artículo queda completado a través de una lectura inicial del diario de campo, producto del inicio de la investigación y con una serie de conclusiones iniciales sobre dicha investigación y sobre la forma de concebir la ciudad estudiada en relación al concepto de la ciberciudad.

\footnotetext{
${ }^{1}$ Persona de contacto: Pep Vivas i Elias, correo electrónico: pvivasi@uoc.edu

${ }^{2}$ Becario FPU-MEC. Departament d'Antropologia Social i Cultural. UAB
} 


\section{Links en la ciberciudad.}

Estoy accediendo a mi banco on-line cuando de pronto llaman a mi smartphone. Es un cliente de Madrid que me convoca a una reunión urgente al día siguiente por la mañana. Minimizo la pantalla que estaba consultando y confirmo en la agenda del Outlook, sincronizada a mi dispositivo móvil, que a esa hora no tengo ninguna cita. Apunto en la agenda la reunión. Seguidamente abro otra ventana en Internet y entro en la página web de una compañía aérea para adquirir un billete de avión que me permita desplazarme hasta dicha ciudad. Al mismo tiempo -ya que la compañía me lo permite a través de su espacio virtual, y dado que se trata de un viaje de ida y vuelta-, me asigno el asiento en el avión e imprimo la tarjeta de embarque. Cierro definitivamente la ventana de la compañía aérea y vuelvo a maximizar la página de mi banco para acabar de revisar mis cuentas. Se me ha hecho tarde. Salgo de la oficina, situada en un centro comercial, y compro algunos productos en el hipermercado. De camino a la estación de metro recibo unos cuantos e-mails a través de mi dispositivo móvil. Decido que los leeré cuando esté sentado en el tren. Llego a la estación y me doy cuenta de que me he olvidado de comprar un brick de leche, al ver que al lado de las máquinas dispensadoras de billetes hay una máquina que permite adquirir productos alimenticios.

Echo las monedas en la ranura, aprieto los números del dispensador y recojo el brick. Utilizo la tarjeta multiviajes para poder acceder al andén de la estación. Esperando que llegue, hay una pantalla electrónica que me informa el tiempo de espera, me fijo en las pantallas de televisión y en las cámaras de videovigilancia. La puerta del metro se para justo delante de donde yo estoy. Dejo que las personas que bajan en esta estación salgan del metro. Entro al mismo y me siento en un asiento que esta libre. Reviso entonces los e-mails y contesto un par de ellos. Otra vez suena el smartphone. Es mi pareja que me cita en Starburks en el centro de la ciudad. Voy pues hasta este lugar para encontrarme con ella. Tomamos un café $y$, al mismo tiempo, decidimos que vamos a cenar rápidamente una hamburguesa en un Burguer king próximo.

El despertador suena a la hora programada. Me visto y salgo de casa hasta la estación de cercanías. Allí debo coger un tren que me llevará hasta el aeropuerto. El tren llega hasta su destino. Hay una pantalla en el andén que me indica cual es la puerta de embarque de mi avión. A través de un pasillo que conecta la estación del aeropuerto con las diferentes terminales me dirijo hasta el punto indicado. Enseño mi tarjeta de embarque para poder pasar el control de seguridad y entrar a la zona duty free. Me siento en la mesa de un bar y desayuno antes de entrar en el avión. En ese momento, conecto mi pc portátil a Internet para revisar los últimos e-mails recibidos y consultar las noticias de los periódicos digitales. La voz del altavoz llama al embarque a los pasajeros de mi vuelo. Le doy la tarjeta de embarque al empleado de la compañía para poder acceder finalmente al avión. Durante el viaje escucho música a través de mi pc. El avión aterriza a la hora esperada en la T4. Enciendo mi dispositivo móvil. Me llegan varios mensajes de llamadas perdidas y los últimos e-mails. Me fijo en los carteles que me indican donde está la salida y, a la vez, donde se encuentra ubicada la estación de metro de la terminal. Antes de llegar al andén recibo una llamada de un cliente de Bilbao. Tenemos una larga discusión sobre un producto. Ello hace que casi no me de cuenta de que ya estoy en el centro de la ciudad, lugar de mi cita profesional. Miro mi agenda: es la hora indicada. Acabo la reunión programa. Salgo del edificio y paro un taxi para que me lleve hasta el hotel. Llego al mismo pero antes de subir a la habitación decido conectarme de nuevo a la red. Entro al portal de mi universidad. Escribo mi login y mi password y accedo al campus virtual. Reviso el foro de mi aula.

La experiencia que hemos relatado es un extracto de la ciudad actual en la que estamos inmersos y en la que, con mayor o menor intensidad, realizamos prácticas sociales como las que acabamos de explicar. Así pues, la realidad urbana que presentamos aquí pone de manifiesto la influencia que la tecnología tiene sobre la urbe a partir de las diferentes formas en las que mediatiza las relaciones, las interacciones y la movilidad de los ciudadanos/as. Este 
ejemplo también destaca la multiplicidad de espacios que habitamos, apenas sin darnos cuenta: espacios próximos, lejanos, conectores e intermedios. La ciudad actual -la ciberciudad del presente, como nos gusta decir- se experimenta a través de la variedad de los espacios urbanos que visitamos -sean estos presenciales o virtuales-. En ella realizamos un sinfín de acciones sociales y tecnológicas que provocan que las fronteras entre la realidad física y la realidad virtual se desdibujen. De esta manera, la ciberciudad, como imbricación de ambas realidades, recopila en su interior prácticas presenciales y virtuales que hacen que más que habitar las urbes las traspasemos, es decir, que vivamos en un flujo constante de imágenes, actividades, interacciones y procesos característicos de la sociedad urbana actual. Las fronteras entre unos aspectos y otros quedan difuminadas constante y cotidianamente. Como muestra el ejemplo, somos capaces de estar a punto de embarcar en un sala de un aeropuerto mirando en la pantalla la hora prevista de salida del avión, leyendo el correo electrónico en nuestro pc, conversando con otra persona a través de nuestro teléfono móvil, etc. De esta forma, habitamos y practicamos en y de diferentes realidades urbanas día a día, instante a instante... y lo hacemos ya de forma automática. Las experiencias urbanas actuales son posibles gracias a los links que provocan que los diferentes espacios de la ciberciudad se puedan conectar. En otras palabras, pasamos por diferentes espacios urbanos conectados a través de otros conectores y en el ejercicio o proceso del estar "yendo" vamos adquiriendo conocimiento sobre lo urbano, sobre como se configura actualmente. Es un conocimiento mediatizado por la tecnología; un saber que se va incorporando a nuestras subjetividades individuales e intersubjetividades colectivas.

En este artículo vamos a tratar de analizar, en el segundo apartado, la ciberciudad actual -o la ciudad del presente- a través de algunos espacios urbanos donde la tecnología está muy presente. En el tercer apartado, presentamos lo que nosotros denominamos como espacios de sociabilidad transitoria como espacios característicos de las urbes actuales. A continuación, exponemos tres ejemplos de estos espacios en el contexto de Barcelona. En el quinto apartado explicamos nuestro método de trabajo para investigar las ciberciudades: la etnografía urbana. Asimismo, explicitamos en lugar donde realizamos nuestra práctica etnográfica: el metro de Barcelona. El artículo queda completado a través de una lectura inicial del diario de campo, producto de la investigación y con una serie de conclusiones iniciales sobre dicha investigación y sobre la forma de concebir la ciudad estudiada en relación al concepto de la ciberciudad.

\section{Espacios en la ciberciudad.}

Como hemos apuntado en la introducción, las ciberciudades actuales se construyen a partir de un cúmulo de espacios que se interconectan entre ellos y a través de las prácticas, interacciones, movimientos, comunicaciones, deslizamientos, navegaciones, que hacemos por ellos. Es necesario, por tanto, explicar los espacios urbanos no por lo vivido "en el vacío sino [a través de] las relaciones que se superponen y que definen formas de desplazamiento y transportación [mediante] "las interminables conexiones entre las cosas" (Rojas, 1997, pág. 17).

Asimismo, podemos entender los espacios urbanos actuales en el sentido en que Foucault (1986) hablaba de los emplazamientos y de las yuxtaposiciones, es decir, a partir de aquellos espacios que se constituyen como "espacios de vecindad" con otros espacios y que el autor nombró como heterotopías. Los "espacios heterotópicos", en el sentido apuntado por Foucault, adquieren más relevancia en la realidad/ciudad urbana tecnológica híbrida que hemos descrito en el primer punto, dado que en el contexto urbano actual podemos visualizar esa ciudad heterotópica como una urbe repleta de espacios que son y existen en relación a otros espacios, los cuales están conectados mediante diferentes lógicas que los agrupan, los relacionan, los definen y por los cuales vamos pasando instante tras instante. 
Los espacios urbanos contemporáneos son, principalmente, lugares que nos invitan a "pasar", a "estar de paso", a "transitar". Habitamos, pues, en los "ambientes de la movilidad" (Bertolini y Dijst, 2003) y es, entonces, cuando

"la vida social se parece así, por completo, a un conjunto de conexiones múltiples y extendidas, a menudo a largas distancias, organizadas en ciertos nodos. Las movilidades provocan que en diferentes espacios sociales se organicen nuevas formas de vida social en torno a estos nodos como, por ejemplo, las estaciones, los hoteles, las autopistas, los complejos turísticos, los aeropuertos, los complejos de ocio, las ciudades cosmopolitas, las playas, las galerías de arte y las áreas de servicio. Éstos son los lugares del 'movimiento intermitente"' (Sheller y Urry, 2006, pág. 213).

Espacios que se constituyen en "corredores urbanos" relativamente lisos (Lassen, 2006), por los cuales nos podemos mover fácilmente. "Espacios de transición espacial" en los cuales se potencia la concentración de personas en la ciudad tecnológica global (Gottdiener, 2001, pág 10-11; Sheller y Urry, pág. 219). "Espacios trayecto" que ofrecen la posibilidad de ir de un nodo a otro en y por una realidad urbana en la cual se mezclan los aspectos físicos y los aspectos virtuales. "Tubos espaciales", compuestos por ejes y radios, que crean una red estrechamente relacionada con los movimientos rápidos. Recuperamos en este contexto las palabras de Ascher (2004, pág. 345) cuando dice que:

"ir rápido quiere decir hacer pocas paradas, lo cual produce un efecto túnel y optimiza la concentración y la dispersión de flujos a partir de unas plataformas nombradas hubs. Este tipo de organización reticular se extiende no sólo al transporte aéreo, con el desarrollo de inmensas plataformas aeroportuarias, sino también al transporte de mercancías por carretera y tren, con la constitución de plataformas logísticas multimodales la polarización de toda clase de actividades próximas a las estaciones multimodales y a los nodos de carreteras periurbanos".

Las ciberciudades están sufriendo un proceso de transformación (hub)anistico. Así lo expresa Muñoz (2006, pág. 248) al afirmar que, en la actualidad, aflora un nuevo urbanismo que se hace visible "de forma clara en la forma en que alguna redes de última generación se han ido fijando en el territorio". Puntos e infraestructuras de las urbes importantes no sólo por las personas que viven en ellos sino sobretodo por las gentes y objetos que pasan por ellos. Estos hubs o superhubs (como expresa Gethin, 1998 y Graham, 2001) se han convertido en los puntos estratégicos de las grandes ciudades occidentales -no es casual, pues, que en estas plataformas se invierta económicamente- y son los lugares donde las transformaciones urbanas son más visibles, en buena parte con el aumento de la movilidad, incluyendo la forzada (desde el sin papeles hasta el viajero suburbano arrojado de la ciudad por los precios de la vivienda). Paradójicamente, también son lugares donde la inmovilidad se hace más palpable en contraste con dicha supuesta "libertad de movimiento" (por ejemplo, al lado del hombre de negocios entrando rápidamente en las terminales aeroportuarias podemos encontrar al turista de bajo coste casi parado en largas colas o al migrante económico del sur global complemente inmovilizado).

En definitiva, no nos interesan cualquier tipo de espacios, sino aquellos que contienen o producen un determinado tipo de prácticas (al menos para una parte de las personas que los atraviesan diariamente). Nos parece interesante el análisis de esos territorios de la urbe actual, pero sobre todo de los diferentes actores que los habitan -momentánea o permanentemente-y las formas en las que utilizan (empujados a hacerlo o no, dentro de las normas o no), dichos espacios. Nos importan los

"edificios singulares o conjuntos de edificios caracterizados por ser relativamente autónomos, con lógicas específicas que no necesariamente son las del propio territorio donde se localizan. Han aparecido así espacios con entidad propia en tanto en cuanto son atractores de movilidad 
y generadores de dinámica urbana, pese a no estar necesariamente dentro de la ciudad continua ni tampoco tener forzosamente lo que en términos morfológicos se reconocía tradicionalmente como apariencia urbana. Contenedores de diverso orden -tecnológico, comercial, intercambiadores de flujos de personas, bienes y de información- se disponen así en el territorio en la forma de centros comerciales, museos metropolitanos, parques temáticos, salas multicine o estaciones intermodales y aeropuertos, donde el área de shopping es cada vez más importante. Se trata de puntos en el territorio que organizan los flujos de movilidad a escala regional e incluso global" (Muñoz, 2006, pág. 247).

Estructuras espaciales que están relacionadas no con aquello que permanece sino con aquello que transita con la mayor rapidez posible por las mismas. "Superficies resbaladizas" en los cuales "los eventos, las personas y las cosas transitan impunemente sin dejar huellas, como si fueran 'ladrones de espacio', sombras que no dejan marcas pero que son perceptibles por nuestros sentidos" (Hiernaux, 2006, pág. 277).

Las ciudades del presente son pues ciudades heterotópicas, como apuntábamos antes, dado que "carecen de marcas geográficas al ser hitos espaciales carentes de fijación" (Rojas, 1997, pág. 57), debido a que están repletas de espacios urbanos que son, ellos mismos, espacios que unen lugares, trayectos y experiencias. Están repletas de espacios que "conforman un momento de finitud, en donde las apariencias y las figuras adquieren un sentido momentáneo" (Rojas, pág. 57).

Si partimos de estas formas de concebir los espacios urbanos del presente, es necesario que consideremos que las ciudades actuales ya no se edifican ni se esparcen de una forma estable, sino que las realidades urbanas actuales están estrechamente relacionadas con lo transitorio, con lo efímero, con lo momentáneo, con lo cambiante. Asimismo, necesitamos plantear conceptos sociales que conecten con formas urbanas como las que acabamos de plantear y, que al mismo tiempo, como productos de la realidad urbana en la que están inmersos, nos ayuden a explicar que tipo de prácticas sociales se ponen en juego y que tipo de subjetividad urbana colectiva se están construyendo en la actualidad. Por ello, en el siguiente apartado, describiremos los espacios de sociabilidad transitoria.

\section{La ciberciudad desde los espacios de sociabilidad transitoria.}

Hemos insistido en el punto precedente en la importancia de los espacios o en otras palabras de ver, observar y analizar las ciudades del presente a través de los espacios urbanos que las conforman y que las construyen. En este punto queremos insistir en el tema de los espacios urbanos centrando nuestra atención en aquellos espacios donde la movilidad y la tecnología se convierten en elementos característicos e imprescindibles para la arquitectura física y social de los mismos. Son los espacios que hemos denominado espacios de sociabilidad transitoria.

¿Por qué hablar de espacios de sociabilidad transitoria? En primer lugar, creemos que cualquier concepto vinculado al campo de las ciencias sociales, como tal, se convierte en una herramienta de trabajo y en el foco de interés para observar que fenómenos sociales están sucediendo en nuestras cotidianidades. Por tanto, creemos necesario argüir cómo entendemos los espacios de sociabilidad transitoria y cuales son aquellas características que lo convierten en un elemento indispensable para observar las ciberciudades actuales.

Nos interesa, para comenzar y como ya hemos expuesto en el punto anterior, hablar más de espacios que no de lugares o de territorios para obviar el concepto de los "no lugares" (Augé, 1993) y la controversia entre éstos últimos y los "lugares". Escapamos de los "no lugares" aunque los tenemos en cuenta-, y por tanto de la dicotomía u oposición con los "lugares" para entender más los espacios de sociabilidad transitoria como un producto de las prácticas sociales que realizamos habitualmente, como resultado de las interacciones que mantenemos 
con estos sitios y como consecuencia de las características sociales de las realidades actuales. Además, a partir de lo expuesto en el apartado anterior, consideramos que los espacios de sociabilidad transitoria están especialmente mediatizados e imbricados con las nuevas tecnologías.

Tenemos en cuenta a De Certeau (1984) para describir la primera característica de estos espacios: la cuestión de las prácticas e interacciones sociales. Como cualquier otro espacio, concebimos los espacios de sociabilidad transitoria como lugares practicados; sitios donde no solamente se expresa la materialidad arquitectónica que los construye sino, sobretodo, donde se ponen en juego ciertas formas de relacionarnos, de ser y de hacer. Centrarse en qué tipo concreto de prácticas sociales esta ocurriendo en estos espacios, (por ejemplo, una estación de metro), permite caracterizarlos y además profundizar en las interacciones y las formas de apropiación de los mismos -y en consecuencia de nuestras ciudades-. Si los entendiéramos como un "no lugar" de la forma más estricta (como espacio no identitario, no relacional y no histórico), estaríamos, probablemente, obviando un tipo de prácticas y resaltando otras. Un trabajador, alguien a quien le ocurrió algo importante precisamente en ese andén... para ellos la estación no es un lugar sin significado ni historia. Los ejemplos anteriores lo convertirían sin duda en un espacio relacional y de significado para esas personas. Si bien probablemente es ya un lugar antropológico (aunque de forma superficial) por el simple hecho de ser transitado, esta resignificación del espacio, que en cierto modo realizamos constantemente, y que en la yuxtaposición multiplica su variedad, puede obligarnos a modificar nuestras formas de practicarlo (y analizarlo). El proceso de investigación debe centrarse, por tanto, en las maneras de hacer por una espacialidad no exclusivamente geográfica o geométrica (sino simbólica o semántica), pero además profundamente compleja, cambiante y efímera, en algunos de sus aspectos.

Practicar los espacios requiere de interacción social, y esta se vincula muy habitualmente con el movimiento. Así, las ciberciudades del presente muestran unos escenarios caracterizados por una "movilidad intensiva -derivada de la mayor movilidad de las personas y de la también mayor velocidad a la que se desplazan- $y$, en segundo lugar, un uso intensivo del territorio -al poder cubrir mucha más distancia en los desplazamientos y multiplicar, de hecho, nuestro espacio de vida" (Muñoz, 2006, pág. 240).

En palabras del mismo autor, en el presente nos hemos convertido en unos territoriantes:

"habitantes o residentes de un lugar pero no sólo son eso. Al mismo tiempo, [somos] usuarios de otros lugares y visitantes aun de otros. En otras palabras, son habitantes 'a tiempo parcial', que utilizan el territorio de distinta forma en función del momento del día o del día de la semana y que, gracias a las mejoras en los transportes y telecomunicaciones, pueden desarrollar diferentes actividades en distintos puntos del territorio de una forma cotidiana. El territoriante multiplica así su presencia en el espacio metropolitano hasta el punto de que su relación con él se establece más a partir de un criterio de movilidad, los lugares donde desarrolla actividades, que a partir de un criterio de densidad, el lugar que, estadísticamente, lo fija al territorio según donde esté su residencia principal. El territoriante, por tanto, se define como territoriante entre lugares y no como habitante de un lugar y constituye el prototipo de habitante de los actuales territorios urbanizados" (Muñoz, 2006, pág. 246).

Territoriantes, por tanto, acostumbrados, empujados de ciertos tipos de sociabilidad, o productores de la misma: un concepto que contribuye a insistir en que lo que nos interesa fundamentalmente son las relaciones entre las personas, las interacciones entre ellas y sus movimientos, pero también las relaciones que establecemos con los espacios. Los espacios de sociabilidad transitoria se han convertido en los lugares en los que vivimos, habitamos y nos relacionamos a lo largo de nuestras jornadas laborales y de ocio. Aunque estemos de forma momentánea en ellos, lo cierto es que estos espacios acaban adquiriendo un cierto significado 
simbólico y social. Esta significación de los espacios de sociabilidad transitoria incide directamente en cómo se construye la subjetividad individual y colectiva de los habitantes de las ciberciudades.

No se trata de quitar $u$ otorgar peso a un elemento $u$ otro (lo espacial, lo social, etc.), sino de entender que la propia distinción, en ocasiones, viene más de nuestra propia incapacidad para categorizar la vida social que de la existencia de ese tipo de dicotomías.

Esta dificultad para (a veces obsesión por) acotar y delimitar la realidad urbana se hace aún más intensa cuando intentamos aplicar un adjetivo al tipo de relaciones y prácticas que pueden estar dándose en estos espacios. Hemos usado la palabra transitorio, porque incorpora al mismo tiempo significados relacionados con lo espacial (tránsito, movilidad, traspaso) y con el tiempo efímero y fugaz. Lo efímero siempre ha formado parte de la vida de las ciudades y puede ser descrito así "como los átomos de las grandes moléculas que son nuestros días" (Hiernaux, 2006, pág. 276). Lo efímero es aquello que da vida a la realidad urbana ya que de forma constante despedaza su estabilidad. Lo fugaz que "se percibía de manera episódica en la vida tradicional: era visto más bien como la irrupción de algo desconocido, y quizás peligroso" ha adquirido "a partir del último tercio del siglo XX una presencia permanente en nuestra cotidianeidad" (Hiernaux, 2006, pág. 276).

En definitiva, con el concepto de espacio de sociabilidad transitoria pretendemos entender los espacios urbanos desde las prácticas y los procesos sociales no fijos, desde las movilidades que los atraviesan, desde el significado y los efectos que éstos tienen para la personas y para las ciberciudades, desde y entre el transitar por los espacios: hablar de estos espacios en proceso constante de transformación y como creadores de intersubjectividades nómadas y transitorias que no se pueden anclar a ningún territorio.

\section{La ciberciudad en transformación.}

Las ciberciudades en la actualidad sufren grandes transformaciones al construir, en su territorio, espacios complejos que pueden implicar dichos procesos de sociabilidad transitoria. Podríamos citar aquí un sinfín de proyectos urbanos que se han llevado a cabo en diferentes urbes del mundo, por ejemplo: la nueva terminal aérea T4 de Madrid, la construcción del metro de Málaga, la nueva estación de tren Berliner-Hauptbahnhof de Berlín, el Tren de Alta Velocidad que a través de un túnel submarino que pasa por debajo del Canal de la Mancha uniendo las ciudades de Londres con París, etc.

En este sentido Barcelona no es una excepción. En el centro del debate y de los proyectos considerados clave para la inserción de esta ciudad en los flujos de la globalización están los nuevos proyectos de infraestructura de movilidad y de conexión de larga distancia (tren de alta velocidad, reforma del aeropuerto y puerto, etc.) y de proximidad (nuevas líneas de metro, servicio de tren de cercanías, cuarto cinturón, etc.).

Algunos ejemplos de estos proyectos -de los espacios de sociabilidad transitoria que mencionábamos en el punto anterior- se están construyendo en la actualidad y son los que se muestran a continuación (figura 1): 
Figura 1. Imágenes virtuales de los futuros espacios de sociabilidad transitoria de Barcelona

a) Estación del AVE Sagrera

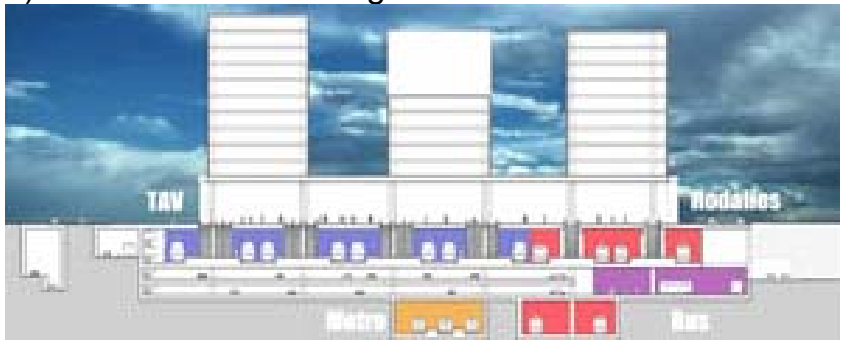

c) Terminal Sur aeropuerto del Prat

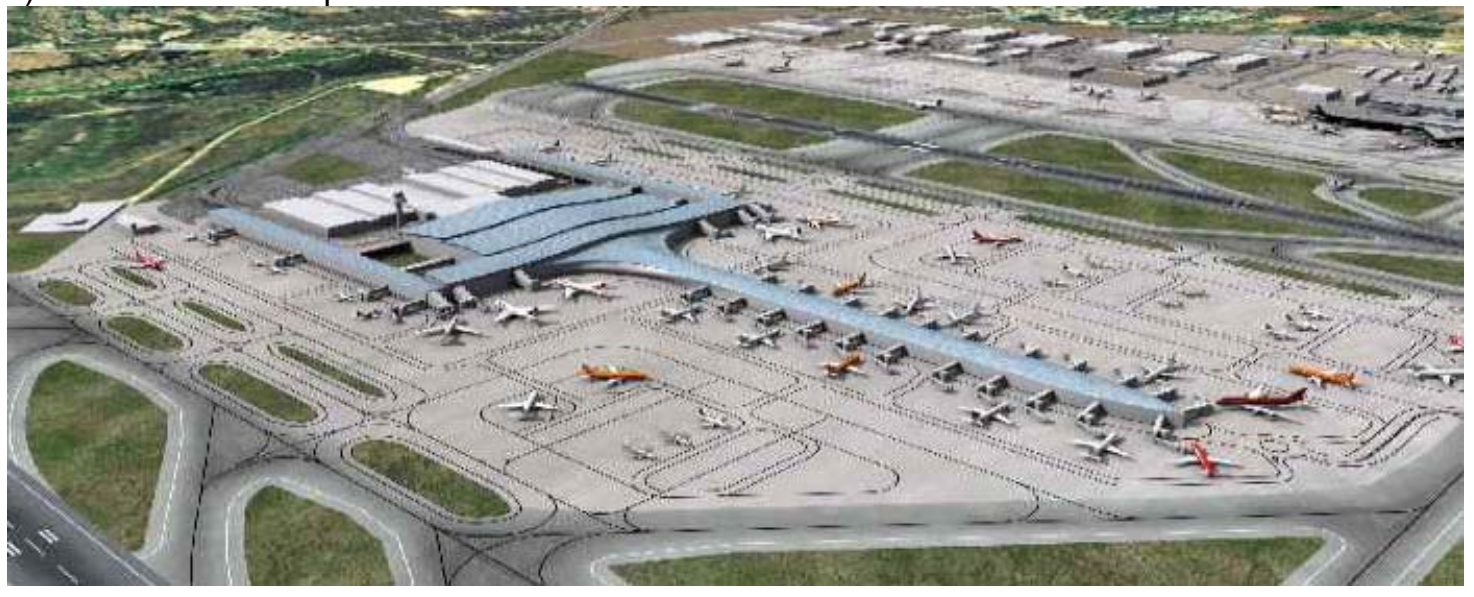

b) Estación y andén Línea 9 del metro

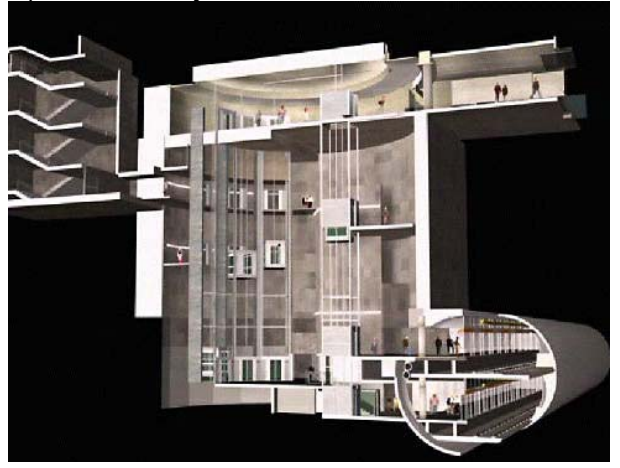

Fuente: a y b) www.gencat.cat; c) www.aena.es

La futura estación de Alta Velocidad de la Sagrera, aún por construir, asegurará no sólo el tráfico de los trenes de alta velocidad, sino que también doblará la capacidad de la frecuencia de los trenes de cercanías del área de Barcelona. Así pues, en esta estación habrá 22 vías: 10 de alta velocidad, 8 de trenes de cercanías -en un primer nivel- y 4 de metro -en un tercer nivel- de las líneas 4 y 9 . En este nuevo espacio nodal para la movilidad de la ciudad, el nivel intermedio servirá como vestíbulo de intercambio y también acogerá áreas destinadas al aparcamiento de coches y a la estación de autobuses. Se prevé que pasarán por esta estación más de 60 millones de usuarios cada año. Esta infraestructura provocará en el entorno más próximo una considerable transformación urbana, convirtiéndose en un "punto de paso obligado" de Barcelona, en un nuevo centro nodal de la ciudad. En la misma estructura arquitectónica o a su alrededor se localizarán oficinas, comercios, viviendas y equipamientos.

Por otra parte, la línea 9 de metro -actualmente en construcción será, con un recorrido de 43 kilómetros, la más larga de Europa. Cruzará toda la ciudad con el objetivo de conectar barrios o zonas que en la actualidad todavía no disponen de este transporte público: por ejemplo, el eje Carlos III-Ronda del Mig-Travessera de Dalt y el eje de Sant Martí-La Sagrera. Además, enlazará la urbe con otros puntos logísticos importantes como, por ejemplo, la zona de actividades logísticas del puerto (ZAL), la Zona Franca y el Aeropuerto del Prat. Asimismo, su construcción también comportará la conexión o nuevas conexiones con otras ciudades y municipios vecinos como, por ejemplo, el Prat de Llobregat, Hospitalet, Santa Coloma de 
Gramenet, Badalona, etc. Cabe destacar dos cuestiones importantes de esta infraestructura: la primera, que el "tubo" del metro pasará a gran profundidad -así se evitan las otras líneas de metro, de ferrocarril y otros servicios: red de alcantarillado, red de telefonía, etc. Así pues, "las estaciones de la L9 tienen una profundidad de entre 35 y $70 \mathrm{~m}$, ya que la línea tiene que cruzar todas las otras líneas del metro. En la mayor parte del trazado, el túnel se ha diseñado de manera que permita colocar una vía encima de la otra. [...] Las estaciones de la L9 se han diseñado de forma vertical. En un nivel superior, a la altura de la calle, encontraremos el vestíbulo. $Y$ en un nivel inferior, el andén. Unos ascensores de alta capacidad y de desplazamiento rápido unirán un nivel y el otro, coordinados con la llegada del tren al andén" (www.gencat.com).La segunda característica es la construcción de 46 estaciones, 16 de las cuales serán intercambiadores con otros medios de transporte: Metro, Ferrocarrils de la Generalitat, cercanías de Renfe, AVE, etc.

Por último, la terminal sur del Aeropuerto de Barcelona entrará en servicio, previsiblemente, durante la primavera de 2009. La construcción de este espacio de tráfico está enfocada desde dos perspectivas: la primera considera la terminal como un nodo de comunicaciones y, la segunda, como un centro de servicios. Así pues, este edificio será un complejo estructurado alrededor de tres elementos. El primero, un edificio procesador -donde se facturará, se recogerán los equipajes y habrá una zona comercial. El segundo, un elemento conformado por dos espacios accesorios laterales y uno longitudinal destinados al embarque de pasajeros. $Y$ finalmente, el tercero, que se convertirá en un centro de transportes o vestíbulo internodal, es decir, el espacio donde esta terminal se conectará con los otros medios de transporte de la ciudad (línea 9 del metro, autobuses, taxis, etc.).Los objetivos principales de esta ampliación son:

"conseguir una capacidad de 40 millones de pasajeros al año, conseguir una frecuencia de 90 operaciones a la hora, disponer de 90 posiciones para estacionar aviones asistidas por pasarelas telescópicas, alcanzar las 1.900 plazas de aparcamiento, habilitar cerca de 300 hectáreas para el desarrollo industrial y comercial, aumentar el espacio para actividades y servicios de las compañías aéreas" (Martínez, 2003, pág. 6).

Así pues, con la construcción de este nuevo espacio urbano se pretenden asegurar unos índices de movilidad aérea tanto de pasajeros como de mercancías que estarán en consonancia con los índices globales de movilidad de otras ciudades.

Junto con las imágenes cotidianas que se nos presentan a los habitantes, conviven estas imágenes que pretenden configurar la realidad futura de la ciudad de Barcelona. Son imágenes que empiezan a tomar forma física (por ejemplo, las obras del aeropuerto avanzan a buen ritmo y su armazón es visible justo en medio de las dos pistas de aterrizaje y de despegue del Aeropuerto del Prat), y que están diseñadas y planificadas previendo sus impactos en el espacio urbano desde unas determinada ópticas. Algunas de ellas, en el pasado, no han llegado a materializarse, y otras lo han hecho de una forma muy diferente a la inicialmente pensada, y con efectos para los habitantes (o para una parte de ellos) lejanos a los teóricamente pretendidos. Ello revela, aunque no es el espacio para discutirlo, tensiones entre diferentes intereses y actores, pero también -lo que nos interesa más- entre las perspectivas de los planificadores/diseñadores y los usuarios de dichos espacios. En ello tiene mucho que decir las nuevas tecnologías, no sólo porque son necesarias para diseñar, proyectar y construir las infraestructuras que acabamos de describir, sino también porque se han planteado como la pieza principal en la gestión de estas infraestructuras, que asegurará su uso y el tráfico de los ciudadanos.

Dicho de otra manera, se pretende que la tecnología se convierta en un elemento más de la atmósfera de las mismas, que asegure la conexión de los usuarios con los espacios, entre ellos, y con otros espacios. De alguna manera se presupone o se pretende conformar un 
usuario tipo, con determinadas habilidades y necesidades y, por tanto, también unas determinadas maneras de utilizar dichos lugares y otros espacios urbanos. Como afirma Sorkin (2004, pág. 11): “La 'calle mayor' [de la metrópolis] es ahora un espacio entre aeropuertos [...] Liberada de sus centros y de sus límites por los adelantos de las comunicaciones y de la movilidad, así como por el nuevo orden mundial hecho a medida de un único modelo de ciudadanía consumidora, la nueva ciudad amenaza con ser de una uniformidad inimaginables".

A la influencia de la tecnología sobre estos espacios hay que añadir las características arquitectónicas de los mismos. En ellos encontramos una generalización universal de un urbanismo donde se mezclan los ambientes y las prácticas sociales de ocio, consumo, trabajo, viaje, etc. Espacios que se convierten de alguna manera en ageográficos, en aterritoriales, con capacidad para insertarse en cualquier parte de nuestras ciudades.

Barcelona, por tanto, a través de éstos y otros proyectos que también guardan relación con la movilidad (intercambiador Sagrera-Meridiana, intercambiador de la Diagonal, prolongación de la línea 5 del metro hasta la Vall d'Hebrón, prolongación de la línea 3 del metro hasta la Trinidad, etc.), está transformando su realidad urbana y social. En esta urbe, como en las otras, emergen constantemente nuevas infraestructuras tecnológicamente mediatizadas, nuevas arquitecturas de la movilidad, nuevos espacios para que la multitud (o una parte de ella) esté en tránsito, y, por tanto, nuevas prácticas sociales, tecnológicas y urbanas susceptibles de ser observadas y analizadas. Vamos a explicitar, en el siguiente punto, algunas posibles pautas para dicho análisis.

\section{Paseos y escritos de la ciberciudad.}

Como estudiosos de lo urbano, los espacios de sociabilidad transitoria de Barcelona nos ofrecen nuevas oportunidades para estudiar que tipo de urbes se están construyendo en la actualidad desde el punto de vista arquitectónico, urbanístico, económico y social. Como ya hemos dicho, aquello que nos interesa es observar que está pasando (o que pasará) en ellos, qué tipo de prácticas e interacciones sociales se ponen en funcionamiento, cual es el papel de las tecnologías en la mediación de estas prácticas, cómo la tecnología influye en la forma de movernos por estos espacios, cómo los gestiona, etc.

Esta observación debe realizarse de forma global, a partir de la planificación, diseño y puesta en marcha de dichos lugares, pero también, necesariamente, desde dentro mismo de ellos, para observar las prácticas cotidianas que en definitiva los constituyen como espacios sociales. En otras palabras, pretendemos centrar nuestra atención en todo lo planteado anteriormente para entender que dichos espacios no son solamente escenarios donde se producen prácticas, interacciones, movilidades circunscritas a ellos, sino que también se han convertido en elementos sociales imprescindibles para analizar las formas en que las personas viven y subjetivizan el espacio urbano en la actualidad.

Así pues, la realidad urbana que pretendemos observar no está alejada de nosotros. Es mas, la conocemos sobradamente a través de nuestros paseos, trayectos y caminos cotidianos. De esta manera, para poder entrar y observar los espacios que nos interesan hemos de hacer un uso adaptado a sus características de la metodología cualitativa, una etnografía urbana que implique caminar, observar, conversar con otros usuarios, fotografiar, etc. que permita no sólo una descripción y análisis de los elementos presentes en los mismos, sino también el abordaje de la complejidad que contienen desde diferentes puntos de vista.

De esta manera puede ser posible, además de caracterizarlos, poner en evidencia prácticas menos visibles, nuevas o no, que habitualmente quedan ocultas por su propia cotidianeidad, o por su falta de correspondencia con las ideas globalmente construidas sobre dichos espacios. 
Como ejercicio inicial de dicha observación hemos decido realizar una breve etnografía sobre el metro de Barcelona. ${ }^{3}$

En los planteamientos más clásicos, la etnografía va asociada al desplazamiento. Desplazamiento dado que es el etnógrafo el encargado de desplazarse, de viajar, de trasladarse hasta el espacio que quiere observar. Este desplazamiento, que es también social y cultural, resulta imprescindible para que el etnógrafo acceda e intente comprender las realidades culturas de los habitantes: contrastando desde el punto de vista de los "autóctonos" y el suyo propio, teniendo en cuenta las prácticas sociales que allí se ponían en juego, pero también su propio papel en ellas. Siguiendo dichos pasos, en nuestro desplazamiento hemos anotado los detalles, las características, de los espacios del metro por los cuales hemos caminado: aquello que nos rodeaba (colores, olores, sabores, sonidos, etc.) incluyendo las interacciones, los comentarios, las preguntas... Nos hemos sumergido asumiendo el doble rol de usuarios y de observadores, acercándonos y al mismo tiempo tomando distancia de lo que ocurría, transitando y registrando las situaciones y preguntas que iban surgiendo, desde el objetivo general de que un espacio tan complejo como el metro nos permitiera mirar unas determinadas facetas de la ciudad de Barcelona desde nuestra perspectiva general sobre ella.

Todos estos datos sobre el metro de Barcelona como espacio de sociabilidad transitoria han quedado almacenados en un diario de campo. Éste contenía no sólo la información escrita recopilada en la etnografía urbana sino también fotografías, videos, fragmentos de entrevistas, etc. Como ya hemos dicho, creemos que ésta es una forma especialmente adecuada para el estudio de los fenómenos y las realidades urbanas que nos interesan, en consonancia con el planteamiento teórico de partida: el ejercicio de estas prácticas de investigación en estos espacios de sociabilidad transitoria nos puede permite abordar su naturaleza de una forma clara y concisa, pero a la vez situada y rica en información. Aunque puede resultar complejo considerando algunas de sus características específicas (movilidad permanente, cambio y flujo constante)-, la observación directa en dichos espacios se ha mostrado como una práctica que posibilita recoger (aunque inevitablemente no de una forma exhaustiva) la multiplicidad y complejidad de situaciones que se dan en ellos. Finalmente las nuevas tecnologías han tenido un papel principal en el proceso investigador, no sólo por el uso intensivo que se hace de ellas en estos espacios, sino también por su utilidad durante dicho proceso.

\section{Lecturas iniciales de la ciberciudad.}

A continuación (a modo de ejemplo) exponemos una primera lectura preliminar de los datos recogidos en el metro de Barcelona. No hemos incorporado fragmentos de dicho diario sino que hemos preferido realizar una lectura global como primer ejercicio del análisis del mismo.

En el metro de Barcelona la variabilidad de horarios y personajes es inmensa, y sin embargo da la impresión de que algo les une más allá de ello: el tránsito de un punto a otro de la red sin prestar mucha atención -aparte de la orientación- al espacio por el que se mueven. El metro hace particularmente visible la relación entre espacio, tecnología, y movilidad, no sólo porque para que entre en funcionamiento sea necesaria la conexión entre múltiples sistemas tecnológicos y electrónicos (control por ordenador de los trayectos, horarios, etc.), sino también porque estos sistemas entran en juego en la propia regulación de las prácticas e interacciones de los usuarios.

\footnotetext{
3 En la bibliografía sobre lo urbano existen trabajos etnográficos específicos sobre el espacio donde realizamos nuestra investigación: ver Augé (1987). También encontramos etnografías que podemos relacionar con los espacios de sociabilidad transitoria: ver Desjeux, Jarvin y Taponier (1999) o Sorkin (2004). Finalmente, diferentes obras que reflexionan sobre la etnografía de lo urbano: ver Augoyard (1979); Delgado (1999); Delgado (2005) y Delgado (2007).
} 
La propia disposición de los espacios del metro hace que esta sensación de tránsito (y de falta de apropiación y significación) sea más acuciante. El tipo de mobiliario que encontramos en este espacio de sociabilidad transitoria está diseñado para que las personas se queden solamente los instantes necesarios, favoreciendo el control y la gestión y, aparentemente, inhibiendo las interacciones. Un buen ejemplo de ello pueden ser los nuevos vagones de metro, que ya ni siquiera cuentan con asientos situados de forma que permitan una conversación frente a frente. Aparte de los ocasionales grupos de personas que viajan juntos, los usuarios optan por la lectura (de un libro o un diario gratuito), por el uso de aparatos (para música, películas o videojuegos) o, en el andén, por mirar el monitor del "canal metro", consultando ocasionalmente la pantalla que informa del tiempo que falta hasta la aparición del siguiente tren.

Pero las personas no nos dedicamos solamente a transitar por estos espacios de una forma "automática" y sin vacilaciones: estamos acompañados, en todo momento, de un trasfondo no casual y, en ocasiones, sutil, que implica aspectos tan diversos como el consumo, el trabajo, etc.

Lo cierto es que en el metro el usuario se ve abordado con bastante asiduidad por multitud de mensajes acústicos, monitores y paneles (de cierta utilidad, orientados generalmente a informar), pero también por publicidad e incluso por promociones que eligen el metro precisamente por el gran volumen de personas que pasan cotidianamente por él. En este espacio las personas recibimos gran cantidad de información porque el mismo espacio nos ofrece todas las oportunidades para así hacerlo.

El metro es también un lugar de trabajo para multitud de personas, sea este regulado formalmente (personal de TMB, propietarios de bares y tiendas, algunos músicos) o realizado de una forma informal (venta de diversos objetos, mendicidad, otros músicos). Pero es además un espacio que, a partir de la incorporación de las nuevas tecnologías móviles, cada vez más personas aprovechan para realizar parte de sus tareas (usando móviles, PDAs, etc.)

El primer elemento de control que pudimos observar es el del acceso. Además del derivado de su diseño (existen colectivos, como personas con carritos, sillas de ruedas, etc., que ven limitada su movilidad en este espacio), las barreras de acceso a los andenes se abren mediante un sistema de lectura de tarjetas de viajes, y están controladas por personal de seguridad. Las máquinas dispensadoras de billetes están conectadas con redes bancarias para poder comprar los billetes al instante (sustituyendo en algunas estaciones y horarios a las ventanillas).

Pero además es necesario destacar la disposición y la cantidad de dispositivos de vigilancia. Con ello la empresa que gestiona el metro de Barcelona intenta ofrecer a los/as usuarios/as una sensación de seguridad ("para su seguridad esta estación está dotada de cámaras de videovigilancia"). En cierta medida, con todos estos elementos el metro como espacio de sociabilidad transitoria se ha transformado, en las entrañas de la ciudad, en un enorme panóptico en red, que algunas personas pugnan por evitar (saltando las barreras de acceso o apropiándose del espacio - por ejemplo, con pintadas). 
a) Relación entre espacio, tecnología movilidad

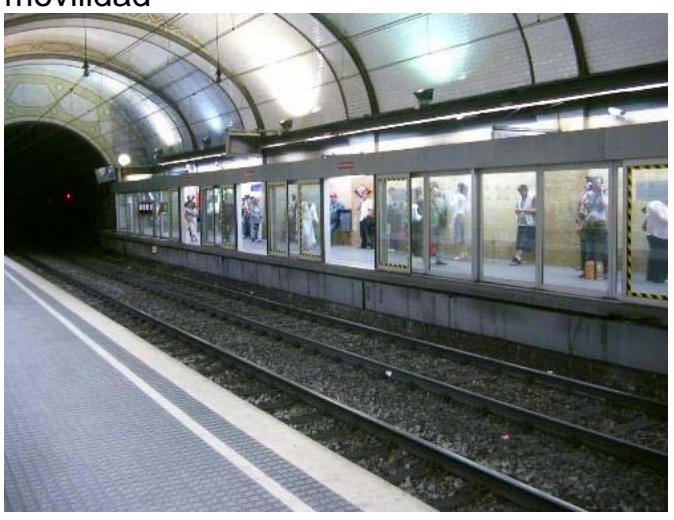

c) Mensajes en el metro

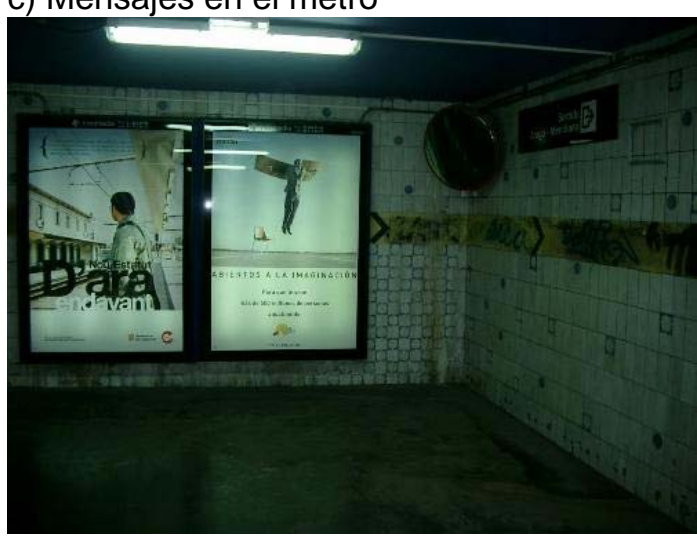

b) Mobiliario del metro
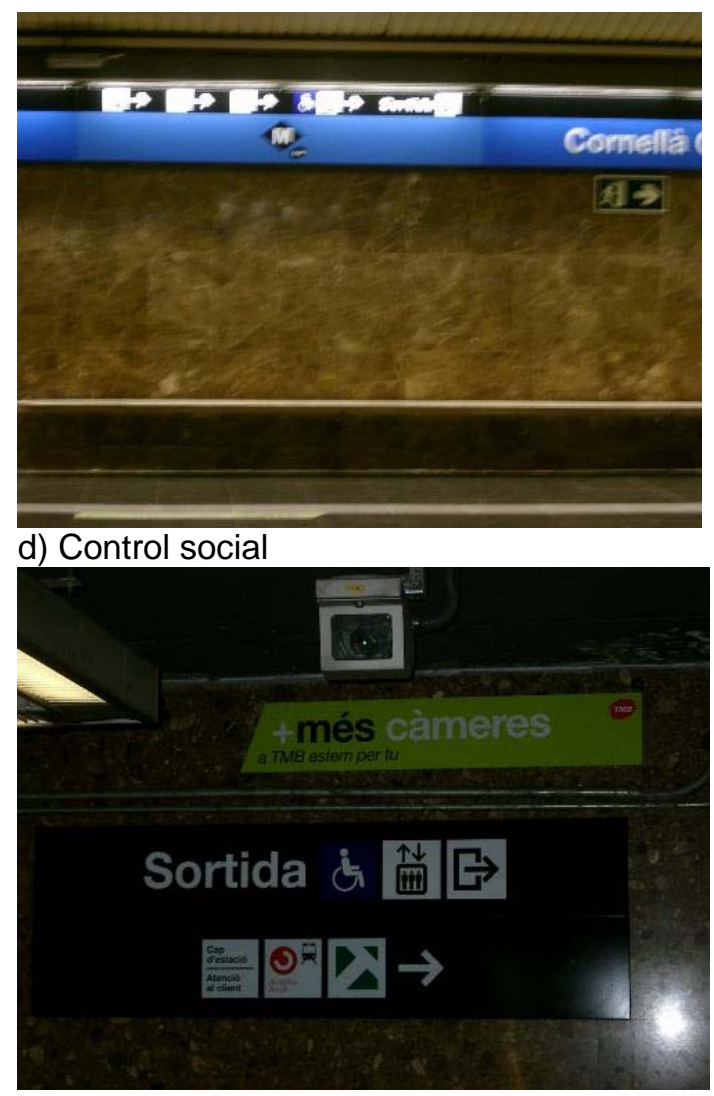

Fuente: elaboración propia

\section{Algunas conclusiones iniciales sobre la ciberciudad}

Creemos que en los espacios de sociabilidad transitoria -como el metro de Barcelona- se ven reflejados, de forma clara, los cambios y las transformaciones que en la actualidad están sufriendo nuestras ciudades. Lo tecnológico juega un papel muy importante en la construcción y la gestión de los mismos y afecta a como las personas interaccionamos con y en ellos. El análisis desde las ciencias sociales de dichos espacios y de los procesos asociados a ellos (la movilidad, el control, la significación, etc.) puede ofrecernos pistas para comprender e intervenir en nuestros espacios urbanos contemporáneos.

Así pues, cuando se finalicen los proyectos que están, en estos momentos, en construcción (los ejemplos ilustrados y mencionados en apartados anteriores) se hará necesario observarlos con detenimiento, ver lo que ocurre en ellos. Tal y como están diseñados, potenciarán y ampliarán la conexión en la ciudad y, en teoría, esto promoverá que las personas que están en movimiento se imbriquen aún más con las tecnologías, los artefactos, las arquitecturas de estos espacios y que se fomenten, a nivel local y global, las conexiones entre los diferentes espacios internos y externos para asegurar una movilidad líquida y fluida. Es innegable que la realidad urbana de Barcelona se está transmutando, mediante la construcción de estos espacios -y mediante el desarrollo de otros proyectos tecnológicos (como, por ejemplo, el 22@)-, para quizás convertirse en una realidad urbana híbrida donde, simultáneamente, podamos vivir una multitud de experiencias tecnológicas y urbanas -productos resultantes al 
vivir en esta mezcla de mundo real/virtual urbano que ya nos rodea actualmente. Pero una de las cuestiones fundamentales es: ¿es siempre el impacto de dichas transformaciones el que teóricamente se pretende conseguir? Es evidente que las nuevas tecnologías están ya, en estos momentos, muy presentes en Barcelona. Con estos nuevos proyectos, -posibles nuevos espacios de sociabilidad transitoria- probablemente la presencia de la tecnología en la calle, en los edificios, en los metros, en los trenes de cercanías, a las estaciones de metro y de tren, etc., todavía será más evidente. La tecnología, en este contexto, condicionará, aun más, las formas de movilidad y la imbricación entre las realidades virtuales y presenciales. Los ciudadanos que se muevan por Barcelona dispondrán, en principio, de unas condiciones óptimas para poder realizar prácticas urbanas mediatizadas por las nuevas tecnologías e interaccionar y comunicarse con ciudadanos que estén en otros espacios físicos o virtuales.

¿Están estos proyectos pensados para todos los ciudadanos, para una parte de ellos o quizás para lo que se pretende que sea un ciudadano/usuario futuro de dichos espacios? En otras palabras, ¿se planifican dichos espacios en función de necesidades actuales, previendo necesidades futuras o también creándolas y configurándolas?

Para dar respuesta a parte de estas preguntas es necesario continuar nuestro trabajo sobre la ciberciudad: sobre dichos espacios en Barcelona, pero también en comparación con espacios similares en otras ciudades. Todo ello nos puede servir para conocer y analizar otros tipos de interacciones y prácticas sociales en espacios de sociabilidad transitoria, para observar cuáles son las características arquitectónicas y tecnológicas de estos espacios, para saber cuáles son las posibilidades de uso y de apropiación de los mismos por parte de sus usuarios, para definir qué procesos pueden influir positivamente en su resignificación y como estos procesos están mediatizados por las nuevas tecnologías. A través de todos estos aspectos realmente contribuiremos a conocer como son las ciberciudades actuales y poder proponer pautas que permitan un mejor uso de los espacios de sociabilidad transitoria tanto a nivel de accesibilidad y la movilidad de las personas como del uso de las nuevas tecnologías.

\section{Referencias bibliográficas.}

Ascher, François. Multi-mobility, multispeed cities: a challenge for architects, town planners and politicians. En: Font, Antoni (ed.). The explosion of the City, Morphologies, Observations and Motions. Barcelona: Col-legi d'Arquitectes de Catalunya: Barcelona, 2004, p. 352-363.

Augé, Marc. Los “no lugares”. Espacios del anonimato. Barcelona, Gedisa, 1993.

Augé, Marc. El viajero subterráneo. Un etnólogo en el metro. Barcelona, Gedisa, 1987.

Augoyard, Jean François. Pas à pas. Essai sur le cheminement quotidien en milieu urbain, París, Seuil, 1979.

Bertolini, Lucia y Dijst, Martin. Mobility Environments and Network Cities. Journal of Urban Desing, 2003, núm 8 (1), p. 27-43.

Certeau, Michel de. The Practice of Everyday Life. Berkeley CA: University of California Press, 1984.

Delgado, Manuel. El animal público. Madrid: Anagrama, 1999. 
Delgado, Manuel. Elogi del vianant. Del "model Barcelona" a la Barcelona real. Barcelona: Edicions de 1984, 2005.

Delgado, Manuel. Sociedades movedizas. Pasos hacia una atropología de las calles.. Madrid: Anagrama, 2007.

Desjeux, Dominique, Jarvin, Magdelana y Taponier, Sophie. Regards anthropologiques sur les bars de nuit. Espaces et sociabilités. París, L'Harmattan, 1999.

Foucault, Michael. Of other spaces. Diacritics, 1986, núm. 16, p. 22-27.

Gethin, Sally. Winning cargo business. Jane‘s Airport Review, 1998, p. 29-21.

Gottdiener, Mark. Life in the Air. Oxford: Rowman and Littlefield, 2001.

Graham, Stephen. FlowCity. Networked Mobilities and the Contemporary Metropolis. DISP, 2001, núm. 4, p. 4-11.

Hiernaux, Daniel. Geografia de los tiempos y de los espacios efímeros y fugaces. En: Nogué, Joan y Romero Joan. Las otras geografías. Valencia: Edicions Tirant-lo-Blanc, 2006, p. 269284.

Lassen, Claus. Aeromobility and Work. Environment and Planning A, 2006, núm. 38, p. 301312.

Martínez, Ramiro. Análisis de las operaciones Hub\&spoke en el transporte aéreo. Aplicación al aeropuerto de Barcelona. Barcelona: Universitat Politècnica de Catalunya, 2003.

Muñoz, Francesc. El tiempo del territorio, los territorios del tiempo. En: Nogué, Joan y Romero, Joan. Las otras geografías. Valencia: Edicions Tirant-lo-Blanc, 2006, p. 235-254.

Rojas, Jesús. Narrativas del Espacio. Una resignificación del espacio en el contexto tecnológico y el pensamiento de finales del siglo XX. Bellaterra: Universitat Autònoma de Barcelona, Tesis doctoral no publicada, 1997.

Sheller, Mimi y Urry, John. The new mobilities paradigm. Environment and Planning A, 2006, núm 38, p. 207-226.

Sorkin, Michael (ed.). Variaciones sobre un parque temático. La nueva ciudad americana y el fin del espacio público. Barcelona, Gustavo Gili, 2004.

: En la solución arquitectónica de la realidad predomina la tendencia a presentarla 
Architecture, City, and Environment

Arquitectura, Ciudad y Entorno 